\title{
Quantitative Methods to Study Protein Arginine Methyltransferase 1-9 Activity in Cells
}

\author{
Magdalena M. Szewczyk ${ }^{1}$, Victoria $\mathbf{V u}^{1}$, Dalia Barsyte-Lovejoy ${ }^{1,2}$ \\ ${ }^{1}$ Structural Genomics Consortium, University of Toronto ${ }^{2}$ Department of Pharmacology and Toxicology, University of Toronto
}

\section{Corresponding Author}

Magdalena M. Szewczyk

magda.szewczyk@utoronto.ca

\section{Citation}

Szewczyk, M.M., Vu, V., BarsyteLovejoy, D. Quantitative Methods to Study Protein Arginine Methyltransferase 1-9 Activity in Cells. J. Vis. Exp. (174), e62418, doi:10.3791/62418 (2021).

\section{Date Published}

August 7, 2021

DOI

$10.3791 / 62418$

URL

jove.com/video/62418

\section{Abstract}

Protein methyltransferases (PRMTs) catalyze the transfer of a methyl group to arginine residues of substrate proteins. The PRMT family consists of nine members that can monomethylate or symmetrically/asymmetrically dimethylate arginine residues. Several antibodies recognizing different types of arginine methylation of various proteins are available; thus, providing tools for the development of PRMT activity biomarker assays. PRMT antibody-based assays are challenging due to overlapping substrates and motif-based antibody specificities. These issues and the experimental setup to investigate the arginine methylation contributed by individual PRMTs are discussed. Through the careful selection of the representative substrates that are biomarkers for eight out of nine PRMTs, a panel of PRMT activity assays were designed. Here, the protocols for cellular assays quantitatively measuring the enzymatic activity of individual members of the PRMT family in cells are reported. The advantage of the described methods is their straightforward performance in any lab with cell culture and fluorescent western blot capabilities. The substrate specificity and chosen antibody reliability were fully validated with knockdown and overexpression approaches. In addition to detailed guidelines of the assay biomarkers and antibodies, information on the use of an inhibitor tool compound collection for PRMTs is also provided.

\section{Introduction}

Arginine methylation is an important post-translational modification that regulates protein-protein and proteinRNA interactions, thus playing an important role in various cellular processes such as pre-mRNA splicing, DNA damage, transcription response, and growth factormediated transduction ${ }^{1,2}$. Arginine is methylated by protein arginine methyltransferases (PRMTs) resulting in monomethyl arginine (Rme1), asymmetrical dimethylarginine (Rme2a), or symmetrical dimethylarginine $(\mathrm{Rme} 2 \mathrm{~s})^{3}$. Based on the methylation type, PRMTs are classified into three groups: Type I (PRMT1, 2, 3, 4, 6, and 8), which catalyze mono- and asymmetric dimethylation; Type II (PRMT5 and 
PRMT9), which catalyze mono- and symmetric dimethylation; and Type III (PRMT7), which can only monomethylate $\operatorname{arginine}^{3}$.

Due to a growing number of commercially available arginine methylation-specific antibodies, PRMT activity can be measured using western blotting. Fluorescent-based western blot is the preferred technique over chemiluminescent detection due to a greater dynamic range and linearity, higher sensitivity, and allowing for multiplexing ${ }^{4}$. To quantify the protein methylation levels, normalization of the methylation signal to total protein levels is required. By choosing the antibodies for total and methylated protein raised in different host species (e.g., mouse and rabbit), secondary antibodies labeled with different fluorophores can be used and the signal for both antibodies can be determined in the same sample band. Methyl-arginine antibodies were developed to identify and characterize monomethylated, asymmetrically, or symmetrically dimethylated proteins where methyl-arginine is found in a specific context. Since the majority of PRMTs methylate glycine- and arginine-rich motifs within their substrates ${ }^{5}$, several antibodies were raised for the peptides containing monomethyl or asymmetric, symmetric dimethyl-arginine-glycine repeats such as D5A12, ASYM24, or ASYM25, and SYM11, respectively. Other methyl-arginine antibodies were generated against a peptide library containing asymmetric, symmetric dimethyl- and monomethyl arginine in a repeat context facilitating the detection of methyl-arginine in these particular contexts ${ }^{6}$. There is also an increasing number of antibodies that recognize specific arginine mark on a single protein which enable selective detection of methylation such as histone H4R3me2a or BAF155-R1064me2a.
There are several commercially available PRMT inhibitors, which can be used as tools for PRMT cellular assays. However, not all of them are thoroughly characterized for selectivity and off-target effects and some should be used with caution. The Structural Genomic Consortium, in collaboration with academic labs and pharma partners, has developed well-characterized potent, selective, and cellpermeable PRMT inhibitors (chemical probes) that can be used with no restrictions by the scientific community. Information on these inhibitors can be found on https:// www.thesgc.org/chemical-probes/epigenetics and https:// www.chemicalprobes.org/. Chemical probes are smallmolecule inhibitors with in vitro IC50 or $\mathrm{K}_{\mathrm{d}}<100 \mathrm{nM}$, over 30fold selectivity over proteins in the same family, and significant cellular activity at $1 \mu \mathrm{M}$. Additionally, each chemical probe has a close chemical analog that is inactive against the intended target $^{7,8,9,10,11,12}$.

The goal of this protocol is to measure the cellular activity of individual PRMT family members using the fluorescent western blot method. Here detailed information on validated assay biomarkers, antibodies, and potent cell-active inhibitors as well as valuable strategies for successful assay implementation are provided.

\section{Protocol}

\section{Cell culturing and plating}

NOTE: Culture cells with recommended media and test routinely for mycoplasma contamination. HEK293T, MCF7, and $\mathrm{C} 2 \mathrm{C} 12$ cells were chosen as examples since these cell lines were successfully used in PRMT assays.

1. Culture HEK293T, MCF7, and C2C12 in DMEM supplemented with $10 \%$ fetal bovine serum (FBS), 
penicillin $\left(100 \mathrm{U} \mathrm{mL}^{-1}\right)$, and streptomycin $\left(100 \mu \mathrm{g} \mathrm{mL}^{-1}\right)$ in $10 \mathrm{~cm}$ tissue-culture treated (TC) dishes.

2. For the PRMT8 assay, grow PRMT1 inducible knockdown HEK293T cells in media containing doxycycline $(2 \mu \mathrm{g} / \mathrm{mL})$ for 3 days before assay start.

3. To plate the cells, remove and discard media from the plate.

4. Add $10 \mathrm{~mL}$ of PBS (without $\mathrm{Ca}^{+2}$ and $\mathrm{Mg}^{+2}$ ions) to wash cells and discard the solution.

5. Add $1 \mathrm{~mL}$ of Trypsin-EDTA (0.25\%), incubate for $1 \mathrm{~min}$ at room temperature (RT), and then discard the solution. Incubate until cells become round and detach from the plate. Tap the plate to help detach cells, if needed. For hard-to-trypsinize cells, such as $\mathrm{C} 2 \mathrm{C} 12$, incubate the plate for $1-2 \mathrm{~min}$ at $37^{\circ} \mathrm{C}$.

NOTE: Avoid cell exposure to trypsin solution for longer periods (>10 $\mathrm{min}$ ) as it will reduce cell viability.

6. Add $1 \mathrm{~mL}$ of prewarmed media to the plate, and gently pipette cells up and down to break-up cell clumps. Transfer cells to a $15 \mathrm{~mL}$ tube, and add 3-5 mL of media.

7. To measure cell number, mix $10 \mu \mathrm{L}$ of cells with $10 \mu \mathrm{L}$ of Trypan blue and transfer $10 \mu \mathrm{L}$ to hemocytometer or use any other cell counting method.

8. Dilute cells to recommended cell density and put $500 \mu \mathrm{L} /$ well into 24-well TC plates (Table 1). For endogenous assays (PRMT1, PRMT4, PRMT5, PRMT7, and PRMT9), move to Step 3.1.

\section{Cell transfection}

1. For exogenous assays (PRMT3, PRMT6, PRMT8) transfect HEK293T cells with the recommended amount of DNA (Table 2). HEK293T cells are easy to transfect so any transfection reagent can be used, following the manufacturer's instruction.

\section{Compound treatment}

NOTE: Do not exceed $0.1 \%$ final dimethyl sulfoxide (DMSO) concentration in culture media. Keep the same DMSO concentration in each well. The selective PRMT inhibitors (chemical probes) and their closely related inactive analogs can be found in Table 3.

1. For endogenous assays (PRMT1, PRMT4, PRMT5, PRMT7, and PRMT9), remove media from cells and replace with $500 \mu \mathrm{L}$ of media with compound or DMSO alone (control).

NOTE: It usually takes 2 days to observe over $80 \%$ decrease in $\mathrm{R}$ methylation levels.

2. For exogenous assays (PRMT3, PRMT6, PRMT8), remove media $4 \mathrm{~h}$ after transfection, add $500 \mu \mathrm{L}$ of media with compound or DMSO alone (control), and incubate for 20-24 h.

\section{Cell lysate preparation}

1. Remove all media from wells, wash with $100 \mu \mathrm{L}$ of PBS to remove residual media, and add $60 \mu \mathrm{L}$ of lysis buffer $(20 \mathrm{mM}$ Tris- $\mathrm{HCl} \mathrm{pH} 8,150 \mathrm{mM} \mathrm{NaCl}, 1 \mathrm{mM}$ ethylenediaminetetraacetic acid (EDTA), $10 \mathrm{mM} \mathrm{MgCl}$, 0.5\% Triton X-100, $12.5 \mathrm{U} \mathrm{mL-1}$ benzonase, complete EDTA-free protease inhibitor cocktail) to each well.

1. Incubate for less than $1 \mathrm{~min}$ at $\mathrm{RT}$, rocking the plate to distribute the lysis buffer over the cells. Then add $3 \mu \mathrm{L}$ of $20 \% \mathrm{w} / \mathrm{v}$ sodium dodecyl sulfate (SDS), to a final $1 \%$ concentration, and mix by gently shaking. Transfer lysate into microcentrifuge tubes and keep it on ice. 
NOTE: Add benzonase and protein inhibitor cocktail fresh before use. The addition of benzonase rapidly hydrolyzes nucleic acids which reduces cell lysate viscosity.

2. Determine protein concentration of the samples using BCA Protein Assay Kit or use any other method which tolerates $1 \%$ SDS in solution.

1. Add $2 \mu \mathrm{L}$ of lysate and protein standards $(0,1,2,4$, and $8 \mu \mathrm{g} / \mathrm{mL}$ of BSA in lysis buffer) into the wells of the 96-well clear plate.

2. Mix reagent $A$ with reagent $B$ at $50: 1$ ratio and add $200 \mu \mathrm{L}$ per well. Incubate for $20 \mathrm{~min}$ at $37^{\circ} \mathrm{C}$ and read the absorbance.

3. Adjust the protein concentration with lysis buffer to be equal across the samples.

4. Add $20 \mu \mathrm{L}$ of $4 \mathrm{x}$ Loading Buffer to $60 \mu \mathrm{L}$ of cell lysate and heat at $95^{\circ} \mathrm{C}$ for $5 \mathrm{~min}$. After heat denaturation, the lysates can be stored at $-20^{\circ} \mathrm{C}$.

\section{Western blot analysis}

1. Load 5-20 $\mu \mathrm{g}$ of total cell lysate for analysis of histone proteins and $20-100 \mu \mathrm{g}$ for other proteins into a $4-12 \%$ Bis-Tris protein gel.

2. Run the gel in MOPS SDS running buffer ( $50 \mathrm{mM}$ MOPS, $50 \mathrm{mM}$ Tris Base, 0.1\% SDS w/v, 1 mM EDTA, pH 7.7) for about $2 \mathrm{~h}$ at $100 \mathrm{~V}$ or until the dye front reaches the bottom of the gel.

3. If performing a wet transfer, assemble the transfer sandwich in ice-cold Tris-Glycine transfer buffer (25 mM Tris, $192 \mathrm{mM}$ Glycine, 20\% v/v methanol, and 0.05\% w/ v SDS).
1. Place sponges, filter paper, PVDF membrane, and gel according to manufacturer's instructions. Activate PVDF membrane by soaking in methanol and equilibrate gel in transfer buffer for $30 \mathrm{~s}$ before assembly.

NOTE: Use recommended PVDF western blotting membrane since it has low autofluorescence and suitability for low molecular weight proteins, such as histones (Table of Materials).

4. Transfer proteins from the gel to PVDF membrane in TrisGlycine transfer buffer at $70 \mathrm{~V}$ for $1.5 \mathrm{~h}$ on ice.

5. Block membrane for $30 \mathrm{~min}$ in blocking buffer $(5 \% \mathrm{w} / \mathrm{v}$ milk in phosphate-buffered saline, PBS). Rinse with wash buffer (PBST: 0.1\% v/v Tween-20 in PBS), and incubate with primary antibodies in bovine serum albumin (BSA) solution (5\% BSA in PBST) overnight at $4{ }^{\circ} \mathrm{C}$ (Table 3).

NOTE: For longer storage, filter-sterilize BSA solution, add $0.02 \% \mathrm{w} / \mathrm{v}$ sodium azide, and keep at $4{ }^{\circ} \mathrm{C}$.

6. Wash membrane $3 \times 5$ min with PBST. Then incubate with goat-anti-rabbit (IR800) and donkey anti-mouse (IR680) antibodies in recommended blocking buffer (Table of Materials, Table 3) for $30 \mathrm{~min}$ at RT and wash $3 \times 5$ min with PBST.

7. Read the signal on a fluorescent western blot imager at 800 and $700 \mathrm{~nm}$. Preferably use the instrument which allows imaging strong and faint bands clearly in a single image with high sensitivity and dynamic range, high signal-to-noise ratio, a warning when an image saturation is reached as well as multiplexing of two fluorescent colors in the same sample band.

8. Determine band intensities for western blot analysis using appropriate software for fluorescent western imaging. 


\section{Representative Results}

Examples of western blot results for cellular assays of individual PRMTs are presented below. Assays details are also summarized in Table 4.

\section{PRMT1 assay}

PRMT1 is the main contributor to histone 4 arginine 3 asymmetric dimethylation (H4R3me2a) in cells ${ }^{13}$. Upon loss of PRMT1 activity, global Rme1 and Rme2s levels increase significantly ${ }^{13}$. As shown in Figure 1A and 1B, several antibodies can be used to monitor global changes in Rme1, Rme2a, Rme2s, as well as H4R3me2a. A significant decrease in global Rme2a and H4R3me2a levels and increases in Rme1 and Rme2s can be observed after 3 days of PRMT1 knockdown (Figure 1A, B). Cell lines differ in basal H4R3me2a signal, therefore, to facilitate monitoring the loss of PRMT1 activity, cell lines such as MCF7 with high basal methylation levels can be used (Figure 1C). The optimal time to observe the effect of PRMT1 inhibition, e.g. upon treatment with type I PRMT inhibitor $\mathrm{MSO23}^{8}$, is 2 days (Figure 1D,1E). Longer treatment results in reduced cell viability and growth.

\section{PRMT3 assay}

For the PRMT3 cellular assay, no selective biomarker proteins which methylation changes could be detected in western blot upon PRMT3 knockdown or overexpression. PRMT3 was shown to asymmetrically dimethylate H4R3 in vitro ${ }^{14}$, however, the mark is predominantly deposited by PRMT1, and therefore an exogenous assay with overexpressed PRMT3 was designed. Consistent with in vitro findings, overexpression of wild-type PRMT3 but not its catalytic mutant (E338Q) led to an increase in H4R3me2a levels (Figure 2A). HEK293T cells were used since they have low basal methylation of this mark (Figure 1C).
The assay was further validated with PRMT3 selective inhibitor SGC707 ${ }^{7}$, which inhibited PRMT3-dependent H4R3 asymmetric methylation (Figure 2B).

\section{PRMT4 assay}

PRMT4 asymmetrically dimethylates BAF155 at arginine $1064^{15}$. Since the antibody detecting BAF165-R1064me2a is commercially available, the PRMT4 activity in cells can be monitored by western blot by detecting the changes in the R1064me2a mark levels. The loss of PRMT4 protein or inhibition of catalytic activity with the PRMT4 selective inhibitor, TP-064 ${ }^{10}$, results in a decrease in BAF165R1064me2a levels (Figure 3). A 2-day treatment is usually sufficient to remove most of the methylation signal.

\section{PRMT5 assay}

PRMT5 is responsible for the majority of protein arginine symmetric dimethylation. It has been previously reported that the various SMN complex proteins, including SmBB', are PRMT5 substrates ${ }^{16}$. PRMT5 activity can be monitored by looking at changes in global levels of symmetric arginine dimethylation or symmetric dimethylation of SmBB' proteins. Knockdown of PRMT5, but not PRMT1, 3, 4, 6, and 7 results in a decrease in global Rme2s levels (Figure 4A). In most cell lines, the treatment of cells with PRMT5 selective inhibitors LLY-283 ${ }^{11}$ and GSK591 for 2-3 days suppressed most of the SmBB'Rme2s signal (Figure 4B). Most cells are sensitive to PRMT5 inhibition, which results in a decrease in cell proliferation and cell death with prolonged inhibitor exposure.

\section{PRMT6 assay}

It has been reported that PRMT6 is the main contributor to histone $\mathrm{H} 3$ arginine 2 asymmetric dimethylation (H3R2me2a) in cells ${ }^{17}$. In HEK293T cells, PRMT6 knockdown for 3 days was not sufficient to observe a significant decrease in H3R2me2a levels. However, overexpression of wild type 
PRMT6 but not its catalytic mutant (V86K/D88A) increases levels of H3R2me2a, as well as H3R8me2a and H4R3me2a (Figure 5A). There are several inhibitors that inhibit PRMT6 activity with different potency and selectivity: selective, allosteric PRMT6 inhibitor SGC6870 ${ }^{18}$, PRMT type I inhibitor $\mathrm{MSO23}^{8}$, and PRMT4/6 inhibitor MS049 ${ }^{9}$. All of these inhibited PRMT6 dependent H3R2 (Figure 5B), as well as H4R3 and H3R8 asymmetric dimethylation (data not shown).

\section{PRMT7 assay}

PRMT7 monomethylates arginine 469 in both constitutive and inducible forms of HSP70 (HSPA8 and HSPA1/6, respectively $)^{12}$. Although there are no commercially available antibodies, which detect HSP70-R469me1 levels, the mark can be detected with pan monomethyl antibodies. The loss of PRMT7 protein or inhibition of catalytic activity with the PRMT7 selective inhibitor, SGC $3027^{12}$, results in decreased levels of HSP70-R469me1 (Figure 6A, B). SGC3027 is a cellpermeable prodrug, which in cells is converted by reductases to the PRMT7 selective inhibitor SGC8158, therefore cellular potency may differ between cell lines. Several cancer cell lines express inducible HSP70 isoforms at high levels, and methylation can be hard to detect due to an overlapping unspecific band of nuclear origin (Figure 6C). Therefore, for the PRMT7 cellular assay, cell lines that express mostly HSPA8 such as $\mathrm{C} 2 \mathrm{C} 12$ are recommended, or since HSP70 localizes mainly in the cytoplasm, determine HSP70R469me1 levels in the cytoplasmic fraction of preferred cell lines.

\section{PRMT8 assay}

PRMT8 is the only PRMT with a tissue-restricted expression pattern - largely expressed in the brain ${ }^{19}$. It shares $80 \%$ sequence similarity and has a similar substrate preference as PRMT1 19 . It differs from PRMT1 mainly at the $\mathrm{N}$ - terminus, where myristoylation results in the association of PRMT8 with the plasma membrane ${ }^{20}$. It has been reported that PRMT8 together with PRMT1 methylates RNA-binding protein EWS ${ }^{21}$. Since PRMT8 activity is low in non-neuronal cell lines and EWS can also be methylated by PRMT1, an assay in which PMRT8 is co-overexpressed together with EWS in PRMT1 knockdown cells was developed. Since PRMT1 is an essential gene and its long-term loss results in cell death, an inducible system in which PRMT1 is knocked down for 3 days before use in the PRMT8 assay was utilized (Figure 7A). Co-expression of wild-type PRMT8, but not catalytically inactive mutant (E185Q), together with EWS resulted in increased levels of EWS asymmetric dimethylation (Figure 7B). Several asymmetric dimethylarginine antibodies were tested and the methylation was only detected with Asym25 antibody. The assay was further validated with a PRMT type I selective chemical probe, $\mathrm{MS}_{02}{ }^{8}$, which decreased PRMT8-dependent asymmetric dimethylation of exogenous EWS (Figure 7B). Although MS023 is very potent in inhibiting PRMT8 in in vitro assays, in cells high concentrations of MS023 are required to see methylation inhibition $^{21}$.

\section{PRMT9 assay}

PRMT9 was shown to symmetrically dimethylate SAP145 at arginine $508^{22}$. Unfortunately, no commercially available antibodies can recognize the mark. For the PRMT9 assay, antibodies that were kindly gifted by Dr. Yanzhong Yang (Beckman Research Institute of City of Hope) were used. When overexpressed, wild type but not R508K mutant SAP145 is methylated by PRMT9 (Figure 8A). The assay was designed to monitor the levels of endogenous SAP145R508me2s and was validated with Compound X, a prototype PRMT9 inhibitor (work in progress, not yet published), which potently inhibits PRMT9 in vitro with nanomolar potency. 
Compound $X$ decreased SAP145-R508me2s levels in a dose-dependent manner (Figure 8B).

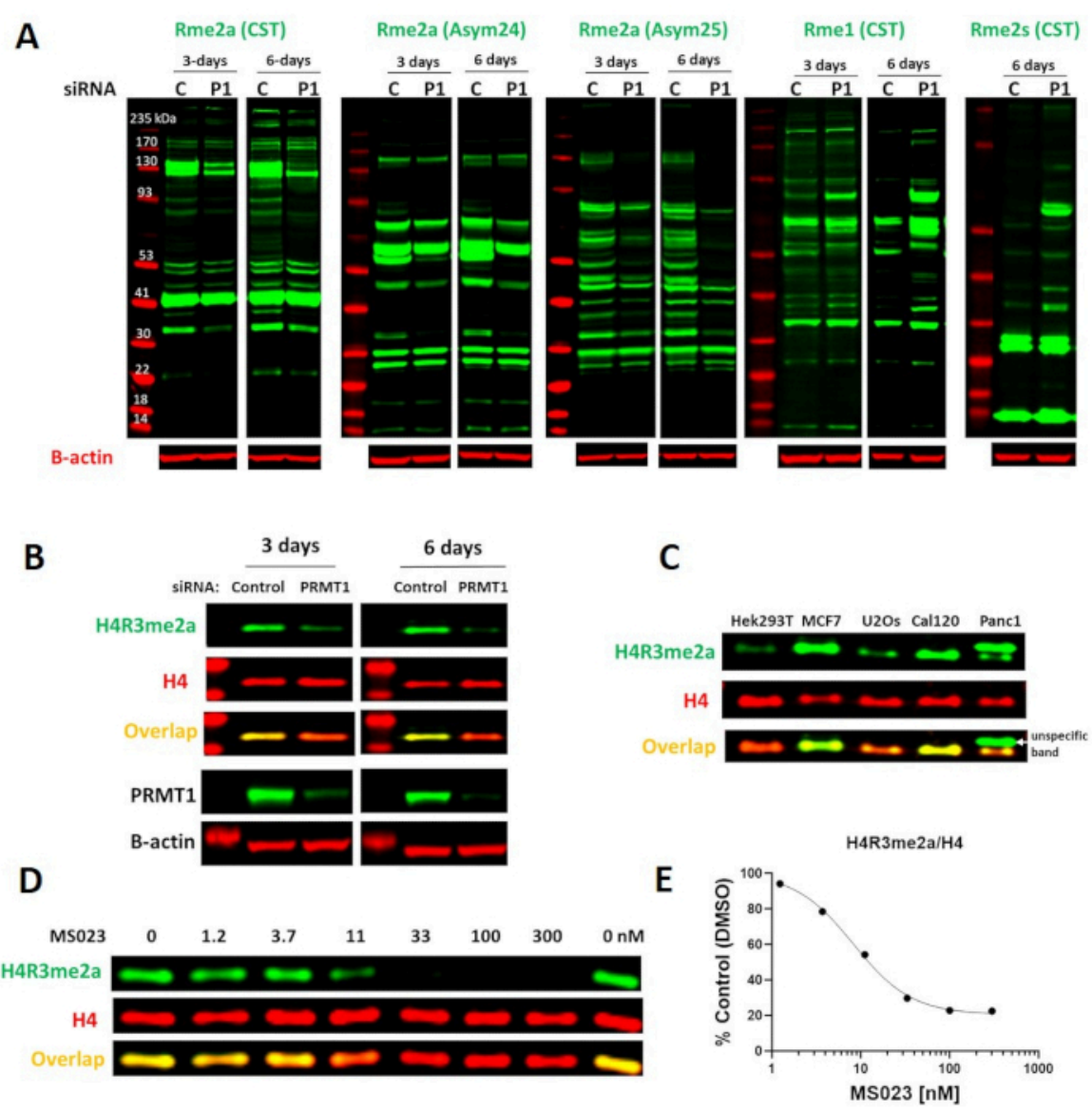

Figure 1. PRMT1 cellular assay. (A) PRMT1 knockdown results in a decrease of global asymmetric arginine dimethylation (Rme2a) and increased levels of symmetric arginine dimethylation (Rme2s) and monomethylation (Rme1). The PRMT1 knockdown efficiency is presented in panel B. (B) PRMT1 knockdown decreases asymmetric dimethylation of histone H4R3 (H4R3me2a). (C) The basal H4R3me2a levels differ across different cell lines. (D) Type I PRMT inhibitor MS023 decreases H4R3me2a levels in a dose-dependent manner. MCF7 cells were treated with MS023 for 2 days. (E) The graph represents the nonlinear fit of H4R3me2a signal intensities normalized to total histone H4. MS023 IC50 = $8.3 \mathrm{nM}(\mathrm{n}=1)$. Please click here to view a larger version of this figure. 
A

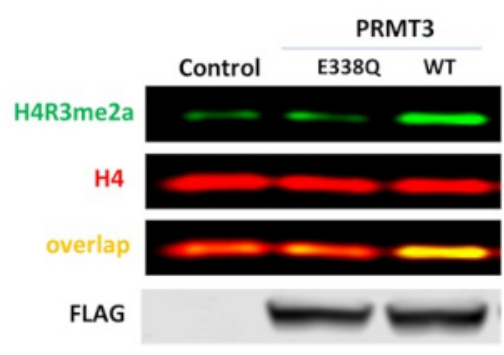

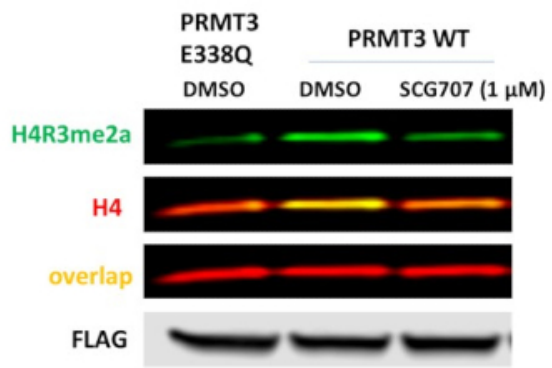

Figure 2. PRMT3 cellular assay. (A) The overexpression of wild-type (WT) but not E338Q catalytic mutant of PRMT3 increases H4R3me2a levels in HEK293T cells. Cells were transfected with FLAG-tagged PRMT3 for 24 h. (B) PRMT3 selective inhibitor, SGC707, decreases ectopic PRMT3 dependent H4R3 asymmetric demethylation Please click here to view a larger version of this figure.

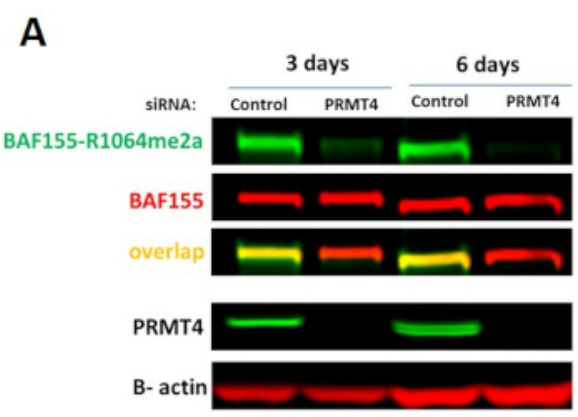

B

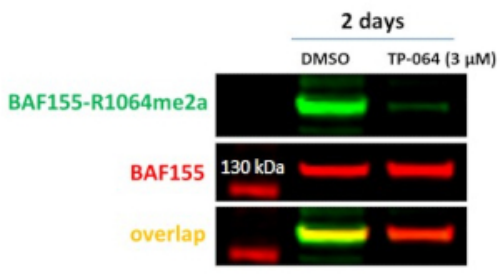

Figure 3. PRMT4 cellular assay. (A) PRMT4 knockdown results in a decrease of BAF155-R1064 asymmetric arginine dimethylation (HEK293T cells). (B) PRMT4 selective inhibitor, TP-064, decreases BAF155-R1064Rme2a levels. HEK293T cells were treated with compound for 2 days. Please click here to view a larger version of this figure. 


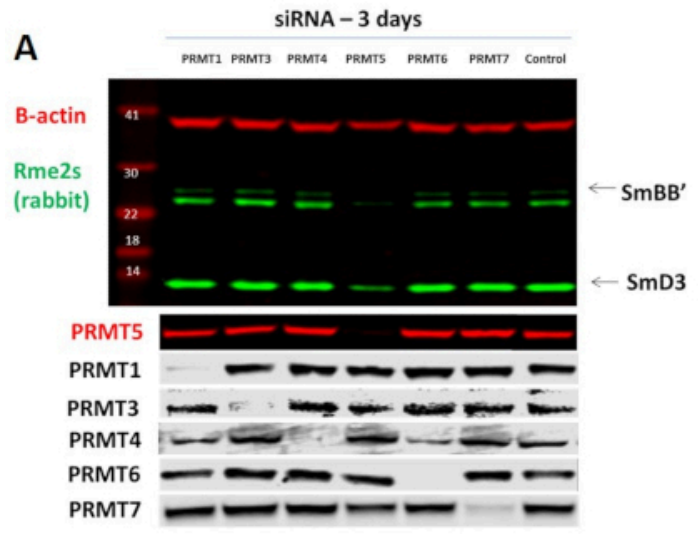

B

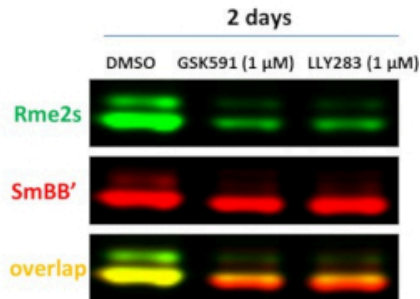

Figure 4. PRMT5 cellular assay. (A) PRMT5 knockdown results in a decrease of global symmetric arginine dimethylation levels (MCF7 cells). (B) PRMT5 selective inhibitors GSK591 and LLY-283, decrease SmBB' symmetric arginine dimethylation (green), while total levels of SmBB' remain unchanged (red). MCF7 cells were treated with compounds for 2 days. Please click here to view a larger version of this figure. 

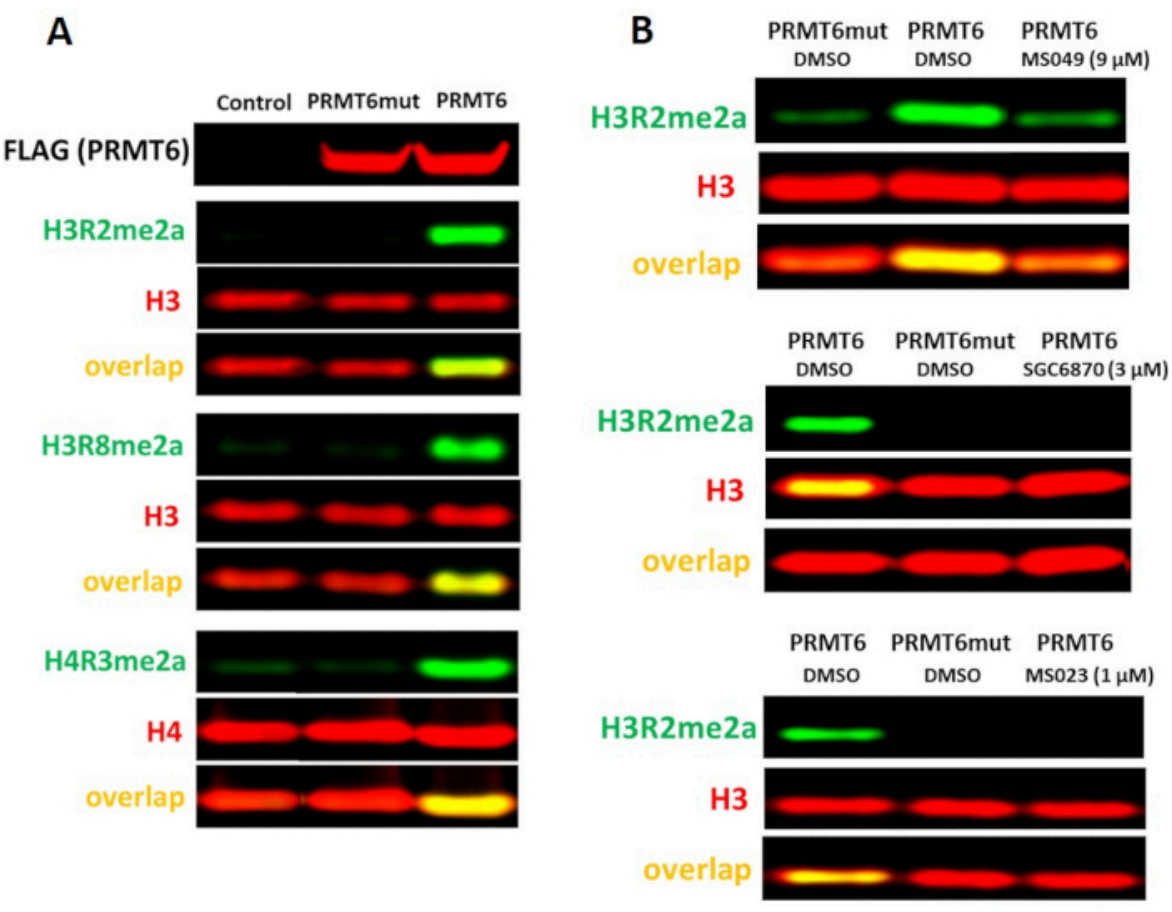

Figure 5. PRMT6 cellular assay. (A) The overexpression of wild type (WT) but not V86K/D88A catalytic mutant PRMT6 increases H4R3me2a, H3R2me2a, and H3R8me2a levels in HEK293T cells. Cells were transfected with FLAG-tagged PRMT6 for 24 h. (B) PRMT6 selective inhibitor (SGC6870), PRMT type I inhibitor (MS023), and PRMT4/6 inhibitor (MS049) decrease PRMT6 dependent H3R2me2a levels. Please click here to view a larger version of this figure. 
A

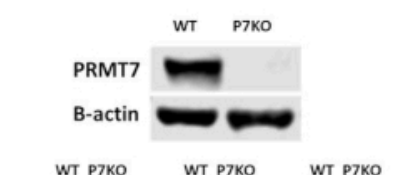

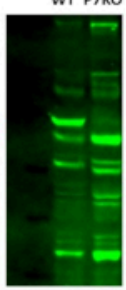

HSP70

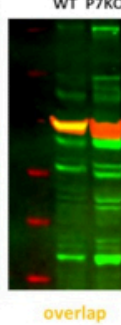

\section{B}

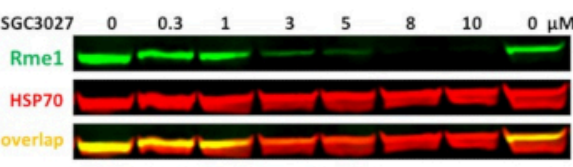

C

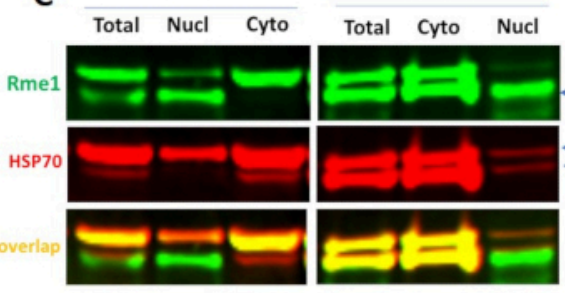

nuclear specific band

overlapping with HSP7

R469me1

HSPAB (constitutive)

- HSPA1/6 (inducible)

Figure 6. PRMT7 cellular assay. (A) PRMT7 knockout results in a decrease of HSP70-R469 monomethylation (HCT116 cells). (B) PRMT7 selective inhibitors, SGC3027, decreases HSP70-R469 monomethylation in C2C12 cells. Cells were treated with compound for 2 days. (C) Detection of HSP70-R469 methylation of inducible HSP70 (HSPA1/6) with pan monomethyl arginine antibodies (Rme1) can be difficult due to an overlapping unspecific band of nuclear origin. It is recommended to measure HSP70 methylation levels in the cytoplasmic fraction. Please click here to view a larger version of this figure. 
A

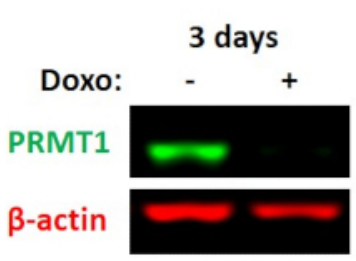

B

PRMT1 KD

PRMT8 PRMT8 WT
E185Q

Rme2a (Asym25)

GFP(EWS)

overlap

DMSO DMSO MS023 $(50 \mu \mathrm{M})$

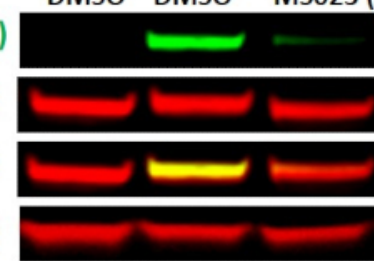

Figure 7. PRMT8 cellular assay. (A) PRMT8 methylation of EWS can be detected when PRMT1 activity is inhibited by knockdown. HEK293T cells were transduced with an inducible PRMT1 knockdown vector. After 3 days of doxycycline treatment, PRMT1 levels were drastically reduced. (B) When PRMT1 is knocked down, exogenous EWS is asymmetrically dimethylated by overexpressed wild type PRMT8 but not catalytic mutant (E185Q) of PRMT8. The methylation is decreased by a high concentration of PRMT type I inhibitor (MS023). HEK293T PRMT1KD cells were co-transfected with FLAG-tagged PRMT8 wild type or catalytic mutant and GFP-tagged EWS and treated with MS023 for $20 \mathrm{~h}$. Please click here to view a larger version of this figure.

A

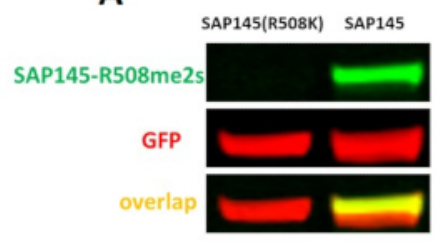

B $\begin{array}{llllllll}\text { Compound } \mathrm{X} & 0 & 10 & 3 & 1 & 0.3 & 0.1 & 0 \mu \mathrm{M}\end{array}$ SAP145-R508me2s SAP145 $130 \mathrm{kDa}$

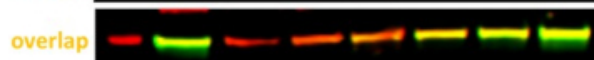

Figure 8. PRMT9 cellular assay. (A) Wild type but not R508K mutant SAP145 is methylated by PRMT9. HEK293T cells were transfected with GFP-tagged SAP145 for 1 day. (B) The prototype PRMT9 inhibitor (Compound X) decreases PRMT9 dependent R508 symmetric dimethylation of SAP145 in a dose-dependent manner. HEK293T cells were treated with the compound for 2 days. Please click here to view a larger version of this figure. 


\begin{tabular}{|c|c|c|}
\hline PRMT & Cells & Density per ml \\
\hline PRMT1 & MCF7 & $1 \times 10^{5}$ \\
\hline PRMT3 & HEK293T & $2 \times 10^{5}$ \\
\hline PRMT4 & HEK293T & $1 \times 10^{5}$ \\
\hline PRMT5 & MCF7 & $1 \times 10^{5}$ \\
\hline PRMT6 & HEK293T & $2 \times 10^{5}$ \\
\hline PRMT7 & C2C12 & $1 \times 10^{5}$ \\
\hline PRMT8 & HEK293T (PRMT1 KD) & $2 \times 10^{5}$ \\
\hline PRMT9 & HEK293T & $2 \times 10^{5}$ \\
\hline
\end{tabular}

*treat cells with doxycycline $(2 \mu \mathrm{g} / \mathrm{mL}) 3$ days before plating for PRMT8 assay

Table 1. Cell types and densities recommended for PRMT assays. 


\begin{tabular}{|c|c|c|c|}
\hline PRMT & $\mu g$ DNA/24-well & Addgene \# & Additional notes \\
\hline \multirow[t]{2}{*}{ PRMT3 } & 0.5 FLAG-PRMT3 & 164695 & \\
\hline & $\begin{array}{c}\text { or } 0.5 \text { FLAG- } \\
\text { PRMT3 (E338Q) }\end{array}$ & 164696 & \\
\hline \multirow[t]{2}{*}{ PRMT6 } & 0.5 FLAG-PRMT6 & 164697 & \\
\hline & $\begin{array}{c}\text { or 0.5 FLAG- } \\
\text { PRMT6(V86K/D88A) }\end{array}$ & 164698 & \\
\hline \multirow[t]{3}{*}{ PRMT8 } & 0.05 EWS-GFP & 164701 & \\
\hline & 0.45 PRMT8-FLAG & 164699 & \\
\hline & $\begin{array}{c}\text { or } 0.45 \\
\text { PRMT8(E185Q)-FLAG }\end{array}$ & 164700 & \\
\hline \multirow[t]{3}{*}{ PRMT9 } & 0.05 SAP145-GFP & NA & \multirow{3}{*}{$\begin{array}{l}\text { gift from Dr. Yanzhong } \\
\text { Yang, Beckman Research } \\
\text { Institute of City of Hope }\end{array}$} \\
\hline & or 0.05 SAP145-R508K-GFP & & \\
\hline & 0.45 empty vector & & \\
\hline
\end{tabular}

Table 2. The DNA concentration recommended for transfection experiment. 


\begin{tabular}{|c|c|c|c|}
\hline PRMT & Antibody & $\begin{array}{l}\text { Chemical probe } \\
\text { (Cell activity IC50) }\end{array}$ & Negative control \\
\hline \multirow[t]{8}{*}{ PRMT1 } & H4R3me2a (1:2000) & MS023 -PRMT type I & \multirow[t]{8}{*}{ MS094 } \\
\hline & Rme1 (1:1000) & $\begin{array}{c}\text { (PRMT1, PRMT6, PRMT3, } \\
\text { PRMT4 IC50 = 9, 56, 1000, } \\
5000 \text { nM, respectively) }\end{array}$ & \\
\hline & Rme2s (1:2000) & & \\
\hline & Rme2a (1:2000) & & \\
\hline & Rme2a (ASYM24, 1:3000) & & \\
\hline & Rme2a (ASYM25, 1:2000) & & \\
\hline & H4 (1:2000) & & \\
\hline & B-actin (1:500) & & \\
\hline \multirow[t]{3}{*}{ PRMT3 } & H4 (1:2000) & \multirow[t]{3}{*}{ SGC707 $($ IC50 = 91 nM $)$} & \multirow[t]{3}{*}{$X Y-1$} \\
\hline & H4R3me2a (1:2000) & & \\
\hline & FLAG $(1: 5000)$ & & \\
\hline \multirow[t]{2}{*}{ PRMT4 } & BAF155 (1:200) & TP-064 (IC50 = 43 nM) & TP064N \\
\hline & $\begin{array}{c}\text { BAF155- } \\
\text { R1064me2a }(1: 3000)\end{array}$ & SKI-73 $(I C 50=540 \mathrm{nM})^{*}$ & SKI-73N* \\
\hline \multirow[t]{2}{*}{ PRMT5 } & anti-SmBB' $(1: 100)$ & LLY-283 (IC50 = $30 \mathrm{nM})$ & LLY-284 \\
\hline & Rme2s (\#13222, 1:2000) & GSK591 $($ IC50 = 56 nM $)$ & SGC2096 \\
\hline \multirow[t]{6}{*}{ PRMT6 } & H4R3me2a (1:2000) & SGC6870 $(I C 50=0.9 \mu \mathrm{M})$ & SGC6870N \\
\hline & H4 (1:2000) & MS023 -PRMT type I & MS094 \\
\hline & H3R2me2a ( 1:2000) & $\begin{array}{l}\text { (PRMT1, PRMT6, PRMT3, } \\
\text { PRMT4 IC50 = 9, 56, 1000, } \\
5000 \text { nM, respectively) }\end{array}$ & \\
\hline & H3R8me2a (1:2000) & $\begin{array}{l}\text { MS049 (PRMT 4, } 6 \text { IC50 = } \\
970,1400 \text { nM, respectively) }\end{array}$ & MS049N \\
\hline & H3 ( 1:5000) & & \\
\hline & FLAG ( $1: 5000)$ & & \\
\hline
\end{tabular}




\begin{tabular}{|c|c|c|c|}
\hline \multirow[t]{2}{*}{ PRMT7 } & Rme1 (1:1000) & \multirow[t]{2}{*}{ SGC3027 $(I C 50=1300 \mathrm{nM})$ * } & \multirow[t]{2}{*}{ SGC3027N* } \\
\hline & $\mathrm{Hsp} / \mathrm{Hsc} 70(1: 2000)^{*}$ & & \\
\hline \multirow[t]{3}{*}{ PRMT8 } & GFP $(1: 3000)$ & \multirow[t]{3}{*}{ 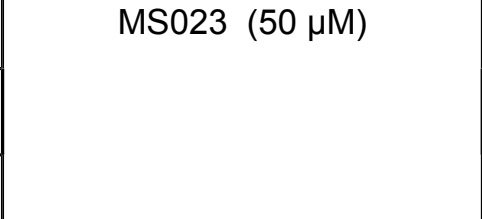 } & \multirow[t]{3}{*}{ MS094 } \\
\hline & Rme2a (ASYM25,1:2000) & & \\
\hline & FLAG (1:5000) & & \\
\hline \multirow[t]{2}{*}{ PRMT9 } & SAP145 (1:1000) & & \\
\hline & $\begin{array}{l}\text { SAP145-R508me2s -kind } \\
\text { gift from Dr. Yanzhong } \\
\text { Yang, Beckman Research } \\
\text { Institute of City of Hope } \\
\text { (1:1000) (PIMID: 25737013) }\end{array}$ & & \\
\hline \multirow[t]{2}{*}{ Secondary antibodies } & $\begin{array}{l}\text { goat-anti-rabbit IgG- } \\
\qquad \text { IR800 (1:5000) }\end{array}$ & & \\
\hline & $\begin{array}{l}\text { donkey anti-mouse } \\
\text { IgG-IR680 (1:5000) }\end{array}$ & & \\
\hline \multicolumn{4}{|c|}{ *- antibody recognizes HSPA8, HSPA1 and HSPA6 (tested with overexpressed } \\
\hline
\end{tabular}

Table 3. Recommended antibodies and PRMT chemical probe/negative control tool compounds. 


\begin{tabular}{|c|c|c|c|c|c|}
\hline PRMT & Biomarker & Assay readout & Assay validation & Recommended cell line & Ref. \\
\hline PRMT1 & $\begin{array}{l}\text { H4R3me2a, Rme1, } \\
\text { Rme2s, Rme2a }\end{array}$ & $\begin{array}{c}\text { H4R3me2a levels } \\
\text { normalized to total } \\
\text { H4 global Rme1, } \\
\text { Rme2a or Rme2s levels } \\
\text { normalized to B-actin. }\end{array}$ & $\begin{array}{c}\text { Knockdown of PRMT1 } \\
\text { decreased basal } \\
\text { H4R3me2a and global } \\
\text { Rme2a levels and } \\
\text { increased global Rme1 } \\
\text { and Rme2s levels in } \\
\text { cells (Fig.1A, B). PRMT } \\
\text { Type I chemical probe } \\
\text { MS023 decreased the } \\
\text { levels of H4R3me2a } \\
\text { in a dose-dependent } \\
\text { manner (Fig. 1D). }\end{array}$ & $\begin{array}{l}\text { Cells differ in basal } \\
\text { H4R3me2a levels (Fig. } \\
\text { 1C). MCF7 cells have } \\
\text { high basal H4R3me2a } \\
\text { levels which makes it } \\
\text { preferable for assays } \\
\text { monitoring the decrease } \\
\text { in PRMT1 activity. }\end{array}$ & 8 \\
\hline PRMT3 & H4R3me2a & $\begin{array}{l}\text { H4R3me2a methylation } \\
\text { levels caused by } \\
\text { exogenous FLAG- } \\
\text { tagged PRMT3 WT or } \\
\text { catalytic E338Q mutant } \\
\text { (background) normalized } \\
\text { to total histone H4 }\end{array}$ & $\begin{array}{c}\text { Overexpression of wild } \\
\text { type PRMT3 but not } \\
\text { its catalytic mutant } \\
\text { (E338Q) increased } \\
\text { H4R3me2a (Fig. 2A). } \\
\text { PRMT3 selective inhibitor } \\
\text { SGC707 decreased } \\
\text { PRMT3 dependent } \\
\text { increase in H4R3me2a } \\
\text { levels (Fig. 2B) }\end{array}$ & $\begin{array}{l}\text { HEK293T cells have } \\
\text { low basal H4R3me2a } \\
\text { levels (Fig 1C), which } \\
\text { is preferable for } \\
\text { monitoring exogenous } \\
\text { PRMT3 activity }\end{array}$ & 7 \\
\hline PRMT4 & BAF155-R1064me2a & $\begin{array}{c}\text { BAF155-R1064me2a } \\
\text { levels normalized } \\
\text { to total BAF155 }\end{array}$ & $\begin{array}{c}\text { PRMT4 knockdown } \\
\text { decreased asymmetric } \\
\text { dimethylation of } \\
\text { BAF155 (Fig. 3A). } 2 \text { day } \\
\text { treatment with PRMT4 } \\
\text { selective chemical probe } \\
\text { (TP-064) decreased } \\
\text { asymmetric dimethylation } \\
\text { of BAF155 (Fig. 3B). }\end{array}$ & Any cell line & 10 \\
\hline
\end{tabular}




\begin{tabular}{|c|c|c|c|c|c|}
\hline PRMT5 & SmBB'-Rme2s & $\begin{array}{c}\text { SmBB'-Rme2s levels } \\
\text { detected with pan } \\
\text { Rme2s antibodies } \\
\text { (CST) normalized } \\
\text { to total SmBB' }\end{array}$ & $\begin{array}{l}\text { Knockdown of PRMT5 } \\
\text { resulted in decreased } \\
\text { SmBB' symmetric } \\
\text { dimethylation levels (Fig. } \\
\text { 4A). } 2 \text { day treatment } \\
\text { with PRMT5 selective } \\
\text { chemical probes, } \\
\text { GSK591 and LLY285, } \\
\text { decreased SmBB'- } \\
\text { Rme2s levels (Fig. 4B). }\end{array}$ & Any cell line & 11 \\
\hline PRMT6 & $\begin{array}{l}\text { H4R3me2a } \\
\text { H3R2me2a } \\
\text { H3R8me2a }\end{array}$ & $\begin{array}{l}\text { H4R3me2a, H3R2me2a } \\
\text { or H3R8me2a } \\
\text { methylation levels are } \\
\text { increased by exogenous } \\
\text { FLAG-tagged PRMT6 } \\
\text { WT but not catalytic } \\
\text { V86K,D88A mutant } \\
\text { (background) normalized } \\
\text { to total histone H4 } \\
\text { or H3, respectively }\end{array}$ & $\begin{array}{l}\text { Overexpression of wild } \\
\text { type PRMT6 but not } \\
\text { its catalytic mutant } \\
\text { (V86K,D88A) increased } \\
\text { H3R2me2a, H3R8me2a } \\
\text { and H4R3me2a levels } \\
\text { (Fig. 5A). Allosteric } \\
\text { PRMT6 inhibitor } \\
\text { (SGC6870), PRMT } \\
\text { type I inhibitor MS023, } \\
\text { PRMT4/6 inhibitor } \\
\text { MS049 decreased } \\
\text { PRMT6 dependent } \\
\text { increase in H3R2me2a } \\
\text { levels (Fig. 5B). }\end{array}$ & $\begin{array}{c}\text { HEK293T cells have } \\
\text { low basal H4R3me2a, } \\
\text { H3R2me2a and } \\
\text { H3R8me2a levels, } \\
\text { which is preferable for } \\
\text { monitoring exogenous } \\
\text { PRMT6 activity }\end{array}$ & 8,9 \\
\hline PRMT7 & HSP70-R469me1 & $\begin{array}{c}\text { HSP70-Rme1 } \\
\text { methylation levels } \\
\text { normalized to } \\
\text { total HSP70 }\end{array}$ & $\begin{array}{c}\text { PRMT7 knockout or } \\
\text { knockdown reduced } \\
\text { HSP70 monomethylation } \\
\text { (Fig. 6A). } 2 \text { day } \\
\text { treatment with PRMT7 } \\
\text { selective chemical probe } \\
\text { SGC3027 decreased } \\
\text { PRMT7 dependent } \\
\text { HSP70 monomethylation }\end{array}$ & $\begin{array}{c}\text { C2C12, HT180 } \\
\text { Several cancer cell } \\
\text { lines express an } \\
\text { inducible form of HSP70 } \\
\text { whose methylation } \\
\text { signal overlaps with } \\
\text { an unspecific protein } \\
\text { of nuclear origin } \\
\text { (Fig. } 6 \mathrm{C} \text { ). In this }\end{array}$ & 12 \\
\hline
\end{tabular}




\begin{tabular}{|c|c|c|c|c|c|}
\hline & & & $\begin{array}{l}\text { in a dose-dependent } \\
\text { manner (Fig. 6B). }\end{array}$ & $\begin{array}{c}\text { case, we recommend } \\
\text { analyzing HSP70 } \\
\text { methylation levels in the } \\
\text { cytoplasmic fraction. }\end{array}$ & \\
\hline PRMT8 & EWS-Rme2a & $\begin{array}{c}\text { Exogenous GFP- } \\
\text { tagged EWS methylation } \\
\text { levels caused by } \\
\text { exogenous FLAG- } \\
\text { tagged PRMT8 WT or } \\
\text { E185Q catalytic mutant } \\
\text { (background), normalized } \\
\text { to total GFP signal } \\
\text { in PRMT1 KO cells. }\end{array}$ & $\begin{array}{l}\text { Overexpression of the } \\
\text { wild type PRMT8 but not } \\
\text { catalytic E185Q mutant } \\
\text { methylated ectopic } \\
\text { EWS only in PRMT1 } \\
\text { KD cells (Fig. 7A). } \\
\text { PRMT type I chemical } \\
\text { probe MS023 inhibited } \\
\text { asymmetric dimethylation } \\
\text { of exogenous EWS } \\
\text { by PRMT8 (Fig. 8B). }\end{array}$ & $\begin{array}{l}\text { HEK293T PRMT1 } \\
\text { KD (inducible). } \\
\text { PRMT1 knockdown } \\
\text { results in cell } \\
\text { death therefore we } \\
\text { recommend using } \\
\text { an inducible system. }\end{array}$ & 8 \\
\hline PRMT9 & SAP145-R508me2s & $\begin{array}{c}\text { PRMT9 dependent } \\
\text { SAP145 symmetric } \\
\text { dimethylation at R508 } \\
\text { normalized to SAP145 }\end{array}$ & $\begin{array}{l}\text { The loss PRMT9 but } \\
\text { not PRMT5 lead to } \\
\text { decreased symmetric } \\
\text { dimethylation of } \\
\text { SAP145. GFP-tagged } \\
\text { SAP145 WT but not } \\
\text { SAP145mut (R508K) } \\
\text { was methylated by } \\
\text { PRMT9 (Fig. 8A). 2-day } \\
\text { treatment with Copound } \\
\text { X, the prototype } \\
\text { PRMT9 inhibitor, } \\
\text { decreased SAP145- } \\
\text { R508me2s levels in } \\
\text { a dose-dependent } \\
\text { manner Fig 8B). }\end{array}$ & Any cell line & 21 \\
\hline
\end{tabular}

Table 4. PRMT assays summary. 


\section{Discussion}

Here, the detailed cellular assay protocols for members of the PRMT family are described that use fluorescent western blotting methods. Unique substrates for which the changes in arginine methylation can be easily detected upon individual PRMT loss or catalytic inhibition and cannot be compensated by other family members were selected. Some proteins are methylated by multiple PRMTs ${ }^{21,23}$, suggesting an overlap in substrate specificity where some PRMTs contribute only a small amount of cellular mark in a given protein substrate $24,25,26,27$, for example, both PRMT8 and PRMT1 contribute to methylation of EWS. Therefore, each assay required thorough validation of substrates and antibodies with knockdown and/or overexpression experiments and further validation with well-characterized selective inhibitors. PRMT specific substrates were identified for which methylation mark changes could be detected within 2-3 days post-PRMT loss/inhibition to avoid compounding effects of reduced cell viability and proliferation that may indirectly affect the methyl-arginine mark levels. Although it was possible to find unique substrates for PRMT1, 4, 5, 7, and 9; for PRMT3, 6, and 8 the gain of function approach had to be employed. Several arginine methyl-specific antibodies were tested for various cellular targets, but none were able to detect significant changes within 3 days of PRMT3 and PRMT6 knockdown; therefore, biomarker assays were developed using ectopically expressed enzymes together with catalytically inactive mutants, which served as a control for the baseline substrate methylation. PRMT8 is a close PRMT1 homolog and shares similar substrate preferences. As a PRMT8 selective biomarker could not be identified, an assay in PRMT1 knockdown cells was developed, where PRMT8 was co-expressed together with EWS. PRMT1 is also a major enzyme responsible for H4R3 asymmetric methylation, therefore, to use $\mathrm{H} 4 \mathrm{R} 3 \mathrm{me} 2 \mathrm{a}$ as a biomarker for PRMT3 and PRMT6 cellular assays, cells with low basal H4R3me2a levels were chosen as well as catalytically inactive mutants were used as a background control. Although endogenous assays are preferred, exogenous assays prove invaluable for testing the cellular potency of several selective PRMT inhibitors ${ }^{7,8,9}$. With growing knowledge of PRMT biology, we expect to improve the assays by finding more specific biomarker proteins for PRMT3, PRMT6, and PRMT8.

The use of validated antibodies and appropriate controls are critical for the PRMT assay performance. All antibodies recommended here have been thoroughly validated by knockdown and overexpression experiments, however, batch-to-batch differences, especially in the case of polyclonal antibodies, may still influence their performance. Therefore, it is crucial to use genetic methods and chemical probes together with their closely related negative controls to confirm assay reliability. Additionally, for PRMT assays that require protein overexpression, it is crucial to use catalytically inactive mutants along with wild-type protein to determine the basal methylation levels.

This collection of quantitative assays for profiling the activity of PRMTs in cells can be broadly useful for the scientific community since it can be rapidly and easily implemented with minimal equipment and limited technical expertise, involving only basic cell culturing and fluorescent western blotting techniques. The recommended antibodies and chemical probes for PRMTs can also be utilized for activity-based protein profiling (ABPP) assays to establish the suitability of a given ABPP probe, monitor target engagement, and assess off-target effects by using the competitive ABPP format. The assay development approaches discussed here can also be 
extrapolated for other enzyme families such as protein lysinemethyltransferases and acetyltransferases.

\section{Disclosures}

The authors do not have any competing financial interests or other conflicting interests to declare.

\section{Acknowledgments}

The Structural Genomics Consortium is a registered charity (no: 1097737) that receives funds from AbbVie, Bayer AG, Boehringer Ingelheim, Genentech, Genome Canada through Ontario Genomics Institute [OGI-196], the EU and EFPIA through the Innovative Medicines Initiative 2 Joint Undertaking [EUbOPEN grant 875510], Janssen, Merck KGaA (aka EMD in Canada and US), Pfizer, Takeda and the Wellcome Trust [106169/ZZ14/Z].

\section{References}

1. Blanc, R. S., Richard, S. Arginine Methylation: The Coming of Age. Molecular Cell. 65 (1), 8-24 (2017).

2. Yang, Y., Bedford, M. T. Protein arginine methyltransferases and cancer. Nature Reviews Cancer. 13 (1), 37-50 (2013).

3. Bedford, M. T., Richard, S. Arginine methylation an emerging regulator of protein function. Molecular Cell. 18 (3), 263-272 (2005).

4. Eaton, S. L. et al. A guide to modern quantitative fluorescent western blotting with troubleshooting strategies. The Journal of Visualized Experiments. 10.3791/52099 (93), e52099 (2014).

5. Thandapani, P., O'Connor, T. R., Bailey, T. L., Richard, S. Defining the RGG/RG motif. Molecular Cell. 50 (5), 613-623 (2013).
6. Dhar, S. et al. Loss of the major Type I arginine methyltransferase PRMT1 causes substrate scavenging by other PRMTs. Science Reports. 31311 (2013).

7. Kaniskan, H. U. et al. A potent, selective and cell-active allosteric inhibitor of protein arginine methyltransferase 3 (PRMT3). Angewandte Chemie International Edition. 54 (17), 5166-5170 (2015).

8. Eram, M. S. et al. A Potent, Selective, and CellActive Inhibitor of Human Type I Protein Arginine Methyltransferases. ACS Chemical Biology. 11 (3), 772-781 (2016).

9. Shen, Y. et al. Discovery of a Potent, Selective, and Cell-Active Dual Inhibitor of Protein Arginine Methyltransferase 4 and Protein Arginine Methyltransferase 6. Journal of Medicinal Chemistry. 59 (19), 9124-9139 (2016).

10. Nakayama, K. et al. TP-064, a potent and selective small molecule inhibitor of PRMT4 for multiple myeloma. Oncotarget. 9 (26), 18480-18493 (2018).

11. Bonday, Z. Q. et al. LLY-283, a Potent and Selective Inhibitor of Arginine Methyltransferase 5, PRMT5, with Antitumor Activity. ACS Medicinal Chemistry Letters. 9 (7), 612-617 (2018).

12. Szewczyk, M. M. et al. Pharmacological inhibition of PRMT7 links arginine monomethylation to the cellular stress response. Nature Communications. 11 (1), 2396 (2020).

13. Goulet, I., Gauvin, G., Boisvenue, S., Cote, J. Alternative splicing yields protein arginine methyltransferase 1 isoforms with distinct activity, substrate specificity, and subcellular localization. Journal of Biological Chemistry. 282 (45), 33009-33021 (2007). 
14. Siarheyeva, A. et al. An allosteric inhibitor of protein arginine methyltransferase 3. Structure. 20 (8), 1425-1435 (2012).

15. Stefansson, O. A., Esteller, M. CARM1 and BAF155: an example of how chromatin remodeling factors can be relocalized and contribute to cancer. Breast Cancer Research. 16 (3), 307 (2014).

16. Pesiridis, G. S., Diamond, E., Van Duyne, G. D. Role of pICLn in methylation of Sm proteins by PRMT5. Journal of Biological Chemistry. 284 (32), 21347-21359 (2009).

17. Guccione, E. et al. Methylation of histone H3R2 by PRMT6 and H3K4 by an mLL complex are mutually exclusive. Nature. 449 (7164), 933-937 (2007).

18. Yudao Shen, F. L. et al. A First-in-class, Highly Selective and Cell-active Allosteric Inhibitor of Protein Arginine Methyltransferase 6 (PRMT6). BioRxiv. https:// doi.org/10.1101/2020.12.04.412569 1-21 (2020).

19. Pahlich, S., Zakaryan, R. P., Gehring, H. Identification of proteins interacting with protein arginine methyltransferase 8: the Ewing sarcoma (EWS) protein binds independent of its methylation state. Proteins. 72 (4), 1125-1137 (2008).

20. Lee, J., Sayegh, J., Daniel, J., Clarke, S., Bedford, M. T. PRMT8, a new membrane-bound tissue-specific member of the protein arginine methyltransferase family. Journal of Biological Chemistry. 280 (38), 32890-32896 (2005).

21. Kim, J. D., Kako, K., Kakiuchi, M., Park, G. G., Fukamizu, A. EWS is a substrate of type I protein arginine methyltransferase, PRMT8. International Journal of Molecular Medicine. 22 (3), 309-315 (2008).
22. Yang, Y. et al. PRMT9 is a type II methyltransferase that methylates the splicing factor SAP145. Nature Communications. 66428 (2015).

23. Rakow, S., Pullamsetti, S. S., Bauer, U. M., Bouchard, C. Assaying epigenome functions of PRMTs and their substrates. Methods. 175 53-65 (2020).

24. Musiani, D. et al. Proteomics profiling of arginine methylation defines PRMT5 substrate specificity. Science Signaling. 12 (575) (2019).

25. Musiani, D., Massignani, E., Cuomo, A., Yadav, A., Bonaldi, T. Biochemical and Computational Approaches for the Large-Scale Analysis of Protein Arginine Methylation by Mass Spectrometry. Current Protein and Peptide Science. 21 (7), 725-739 (2020).

26. Shishkova, E. et al. Global mapping of CARM1 substrates defines enzyme specificity and substrate recognition. Nature Communications. 815571 (2017).

27. Pawlak, M. R., Banik-Maiti, S., Pietenpol, J. A., Ruley, H. E. Protein arginine methyltransferase I: substrate specificity and role in hnRNP assembly. Journal of Cellular Biochemistry. 87 (4), 394-407 (2002). 